\title{
Lesbianidades e as referências legitimadoras da sexualidade
}

\section{Lesbianism and legitimating references of sexuality}

\author{
Livia Gonsalves Toledo \\ Doutoranda pelo Programa de Pós-Graduação em Psicologia da Universidade \\ Estadual Paulista- UNESP, Assis, SP, Brasil
}

\section{Fernando Silva Teixeira Filho}

Prof. Dr. do Depto de Psicologia Clínica e do Programa de Pós-Graduação em Psicologia da Universidade Estadual Paulista - UNESP, Assis, SP, Brasil

\begin{abstract}
RESUMO
Este trabalho é parte de uma dissertação de mestrado que estudou o modo como estigmas e estereótipos a respeito da lesbianidade influenciam a vida, na esfera da sexualidade, de mulheres que se autodenominam lésbicas, residentes em uma cidade do interior do Estado de São Paulo. O estigma aqui analisado é que lésbicas são mulheres que se frustraram com homens. Tentamos mostrar, a partir das narrativas das participantes da pesquisa e baseando-nos nos estudos de gênero e feministas, como o sistema heteronormativo naturaliza a masculinidade aos homens, a feminilidade às mulheres, e legitima os discursos sobre as lesbianidades a partir do referencial da heterossexualidade. Buscamos mostrar, ainda, algumas estratégias do biopoder para a manutenção desse sistema e, a partir de entrevistas em profundidade, apresentamos como as participantes da pesquisa (mulheres que se autodenominam lésbicas) se articulam com esse estigma e o re-significam a partir de suas próprias narrativas. Essa pesquisa foi financiada pela Fundação de Amparo à Pesquisa do Estado de São Paulo - FAPESP, e realizada pelo Programa de Pós-Graduação da Universidade Estadual Paulista - Campus de Assis-SP.

Palavras chave: Gênero, Sexualidade, Lesbianidade, Heteronormatividade.
\end{abstract}

\begin{abstract}
This article is part of a master's degree dissertation that studied the way as stigmas and stereotypes regarding lesbianity influence the life, in the sphere of the sexuality, of women that denominate themselves as lesbians, resident in a city in the interior of the State of São Paulo. The stigma here analyzed is that lesbians are women that frustrated with men. We tried to show, through the narratives of the research's participants and basing on gender and feminist studies, how the heteronormativist system naturalizes the masculinity to the men and the sexuality in the masculinity, and how it legitimates speeches about lesbian woman through the heterosexual
\end{abstract}


referential. Also, we tried to show some strategies of the biopoder for the maintenance of that system and, starting from interviews in depth, we presented how the participants of the research (lesbian women) make speeches on that stigma and how they re-significate it through their own narratives. That research was financed by Fundação de Amparo à Pesquisa do Estado de São Paulo - FAPESP, and accomplished by the Pos-Graduation Program of the Universidade Estadual Paulista - Campus of Assis-SP.

Keywords: Gender, Sexuality, Lesbianity, Heteronormativity.

As tentativas de explicação das homossexualidades têm sido tema recorrente no universo científico e no senso comum: quantidades desajustadas de hormônios, tamanhos anormais dos cérebros ou glândulas, formas corporais, relações familiares desestruturadas são alguns dos referentes das "teorias" formuladas, todos sem comprovação totalmente válida ou fidedigna (CASTAÑEDA, 2007).

O estudo sobre as lesbianidades ${ }^{1}$ não foge a essa lógica de explicação causal, e ainda tem um referencial androcêntrico e heteronormativo. $\mathrm{O}$ androcentrismo é conceituado por Fraser (2002, p. 64-65) como “[...] um padrão institucionalizado de valor cultural que privilegia traços associados com a masculinidade, assim como desvaloriza tudo que seja codificado como 'feminino', paradigmaticamente - mas não somente - mulheres", criando uma hierarquia entre os sexos e os gêneros. A heteronormatividade diz respeito ao sistema de organização da sociedade que pressupõe a heterossexualidade como normal e normativa diante de outras formas de vivência das sexualidades. Deste modo, as normas definidoras da sexualidade "normal" requerem o casal formado por um homem e uma mulher, afetivo-sexualmente complementares, opostos em seus papéis sociais e sexuais - tidos pelo aqui criticado paradigma naturalista, como inerente a cada um dos sexos -, monogâmicos e, preferencialmente, dentro de instituição do casamento. Assim, compõem uma ordem social e sexual na qual são postas expectativas e demandas para homens e mulheres, esperando destes o seguimento das normativas de sexo/gênero/desejo (BUTLER, 2003) baseadas na heterossexualidade, vista como ideal e natural. Desse modo, o que diverge dessa norma é então classificado como imoral, desviante, aberração, doença, pecado e/ou é invisibilizado.

Por isso, crê-se que um dos motivos de uma mulher se relacionar com outra seja devido a uma "falha" na experiência afetivo-sexual com homens. São diversas as versões discursivas explicativas do mesmo estigma. Dentre elas, há a hipótese sobre a frustração amorosa com um homem infiel ou que feriu física ou sentimentalmente a companheira - uma extensão disso é a existência de um "trauma", seja na infância, seja na adolescência ou vida adulta, geralmente no âmbito sexual: abuso sexual, violência 
sexual, estupro; e, por último, a proposição da mulher pouco atraente que os homens não quiseram ${ }^{2}$.

Para a discussão de tal temática, apresentam-se aqui recortes de entrevistas formuladas a partir da identificação de estigmas e estereótipos $^{3}$ sócio-historicamente construídos identificados nos enunciados cotidianos, realizadas com cinco mulheres que se autodenominam lésbicas: três de 18 a 25 anos (Eduarda, Marina e Fernanda), e duas de 40 a 50 anos (Janaína e Marcela ${ }^{4}$ ), residentes em uma cidade ${ }^{5}$ do interior do estado de São Paulo, Brasil. É preciso ter em vista, neste caso, que as conclusões aqui tiradas serão relativas àquele grupo estudado. $O$ que vemos é que todas as "explicações" para as lesbianidades se pautam na figura do homem, e não no autêntico desejo afetivo-sexual de uma mulher por outra:

[Há] várias explicações do porquê que a pessoa é lésbica, né? Menos de que a pessoa é assim porque ela é. Porque falam assim [...] 'Porque foi transar a primeira vez e não quis e achou que com mulher ia ser mais fácil'; Porque o homem bateu; e 'É melhor ficar com mulher, porque mulher é mais sensível', e tal. (informação verbal - Marina, 23 anos)

Para Foucault (1988, p. 70), com o intuito de colocar "em funcionamento uma rede sutil de discursos, saberes, prazeres e poderes", "por volta do século XVIII nasce uma incitação política, econômica, técnica, a falar do sexo" (FOUCAULT, 1988, p. 26). A finalidade disso, segundo o autor, não foi propriamente a de reprimir as sexualidades. Isso foi, ao contrário, o efeito de uma prática muito mais poderosa, pois invisível. Tratou-se, com todos esses discursos, de instaurar modos hegemônicos de sexuação, de prazeres, de condutas sexuais, na tentativa de "normalizar" algumas expressões sexuais em detrimento de outras.

Assim, é possível falar de uma "domesticidade feminina", na qual a sociedade androcêntrica e heteronormativa age diretamente sobre os corpos das mulheres, tornando-os dóceis, submissos e disciplinados. Operam aí mecanismos de controle e autocontrole de sua sexualidade, inclusive daquelas em que o homem não está incluído.

Em relação a pouca ou nenhuma atratividade física como explicação para as mulheres se voltarem a outras, devido à rejeição dos homens, Janaína (47 anos) relata como são incompreendidas as lésbicas mais atraentes dentro desse discurso: "às vezes, alguém perguntou e tá ali: 'Ah, aí, falaram que você, nossa! não acredito que você gosta de mulher mesmo, você é uma pessoa tão bonita'; o que, pra mim, não passa de uma cantada" (Janaína, 47 anos). E Gimeno Reinoso (2005, p. 51) conta como esse discurso não é recente, falando sobre a poetisa Safo da Antiguidade: 
Existe inclusive uma lenda muito antiga que afirma que a morte de Safo ocorreu quando esta se suicidou, jogando-se ao mar da rocha Leucadia, pelo amor não correspondido de um marinheiro. Essa mesma lenda nos informa, ainda, que Safo era pequena e feia, um mito que traz, posteriormente, a idéia de que talvez os amores sáficos com as mulheres se deviam ao fato de que a poeta não era desejada por nenhum homem devido à sua feiúra. Mito este bem conhecido pelas lésbicas de todas as épocas, inclusive a atual. ${ }^{6}$

Eduarda comenta quão grotesca é a simplicidade desta "causa" para as lesbianidades:

\begin{abstract}
É... ridículo [risos]. Porque, é aquela história de gordas e feias, né? As mulheres gordas e feias e caminhoneiras que nunca acharam um homem que as queria e... [risos]. Ai, eu acho, nossa... totalmente sem conhecimento de causa, isso que eu te falo. Porque [risos], porque eu acho que nenhuma pessoa vai ser lésbica, ou vai ser hetero, ou vai ser..., porque nunca encontrou correspondência com nenhuma pessoa do sexo oposto, no caso né? Impossível! (informação verbal - Eduarda, 18 anos)
\end{abstract}

Gimeno Reinoso (2005, p. 286-287) afirma que, atualmente, as lesbianidades só podem ser aceitas se estiverem compatíveis com o androcentrismo e a heteronormatividade, ou seja, de acordo com as normativas de sexo/gênero/desejo (BUTLER, 2003). Denominar-se "lésbica é moderno e admissível sempre que se seja o bastante bela, moderna e glamorosa, e, sobretudo, sempre que, ao final, não se seja de todo lésbica e esteja disposta a ter sexo com os homens". Ela aponta então duas imagens heterossexualizadas das lesbianidades: as chamadas lesbian chic da publicidade contemporânea e as prostitutas que têm atos sexuais entre elas para a satisfação dos homens:

\begin{abstract}
[Assim é a] imagem [das lésbicas do século XXI]: a de mulheres com uma evidente carga erótica (para os homens) e sempre disponíveis (para eles também). É a lesbian chic. A imagem femme da pós-modernidade que nos mostra uma garota muito sexy segundo os parâmetros tradicionais, muito feminina, obviamente, mas, ao mesmo tempo, agressivamente lésbica. [...] é a lésbica que encarna uma das mais persistentes fantasias (hetero)sexuais masculinas.
\end{abstract}

Assim, a mulher lésbica que não se adéqua aos moldes socialmente aceitos "não é sexy, essa não tem graça, a essa há que castigar. Essa é feia, desagradável, não se depila, e se é lésbica é porque os homens nem a olham" (GIMENO REINOSO, 2005, p. 292). São as lesbian chic que têm permissão de aparecer na mídia, enquanto as masculinas ${ }^{7}$ - as "feias" para o sistema heteronormativo, as mulheres 
cuja estética e conduta reproduz aquelas estabelecidas socialmente para o gênero oposto - permanecem invisibilizadas por não estarem de acordo com os modelos exigidos pelo público observador - os homens. Vencato (2005) lembra que há, de fato, uma ausência de lésbicas masculinas nos websites lésbicos internacionais. Ela ainda diz que, no caso do Brasil, o ideal de feminilidade lésbica, especialmente em relação ao ato sexual, pode ter apelo junto ao público heterossexual masculino se pensarmos na fantasia sexual extremamente comum de um homem com duas mulheres na cama (a idéia de ménage sexual).

Portanto, tal como afirma Gimeno Reinoso (2005), uma lesbianidade é permitida desde que não rompa seus vínculos com sistema heteronormativo, desde que os homens heterossexuais possam desfrutar dela, desde que seja apresentada apenas uma imagem heterossexualizada das lesbianidades. Os estereótipos instituídos da lesbian chic ou da lésbica pornográfica/prostituta corroboram com a imagem domesticada das mulheres lésbicas, uma imagem que não atormente a sociedade e suas prerrogativas hegemônicas. O que foge à norma é invisibilizado ou alvo de inconformidade e até violência. Os relatos de Janaína (47 anos) e o exemplo de Lessa (2004) mostram como é incômoda a visibilidade do desejo afetivo-sexual de uma mulher direcionado a outra, e não ao sexo/gênero oposto:

Meus irmãos numa boa, só tive um irmão que, ele não discrimina, ele não briga, ele não fala nada. Mas ele fala assim: ‘Eu não me conformo de olhar pra você e saber que você não gosta de homem. Eu não me conformo. Eu não me conformo. Eu ainda não acredito nisso, deve ter alguma coisa aí que...' [...] E o meu noivo não deixou de me procurar, não deixou de encher o saco. Tanto que esse primeiro relacionamento que eu tive, ele foi, foi, ele se infiltrou na família da moça, até que ele conseguiu. Deu de cima da moça, se mostrou apaixonado por ela. Enfim, atingiu todos os meus pontos fracos. (informação verbal - Janaína, 47 anos)

A marca da lésbica como um ser abjeto é tão presente em nossa sociedade que vemos a fúria com que algumas pessoas escreveram seus comentários: 'Desgraçadas nojentas vão todas arder no fogo do inferno! Vocês só querem aparecer fiquem nuas que é mais fácil. Provem uma pica e vão saber o que é bom' 8 . [...] Dentro dessa instituição discursiva ele ainda afirma que a falta do pênis é o problema maior das lesbianas, pois as mesmas não conhecem o que 'é bom'. A salvação desse inferno é única: adorai o pênis e estarão salvas, pois é inconcebível uma mulher não priorizar o sexo oposto. (LESSA, 2004, s.p.) 
Lago e Paramelle (1978, p. 56) dizem que em uma "sociedade em que o homem tem vergonha de ser tratado por mulher, a atracção recíproca de duas mulheres 'verdadeiramente mulheres' desencadeia a incredulidade, o riso e a proliferação de 'tentativas de explicação' que mascara a inquietação" daqueles capturados pelas normativas de gênero e sexuais. Eduarda conta sobre isso: "meu pai, ótimo, a gente foi numa excursão pra São Paulo, uma vez, e a gente foi pra aquele shopping lá, Frei Caneca', que, né? Enfim! Daí meu pai: 'Eu não posso paquerar uma mulher que a outra fica me encarando!' [risos]" (Eduarda, 18 anos). Nota-se, novamente, nessa fala do pai de Eduarda, a desqualificação da relação lésbica, isto é, ele entende que pode investir em uma mulher, mesmo que acompanhada pela parceira. É conveniente, ainda, um questionamento: se a dita mulher estivesse acompanhada por um homem, sentir-se-ia outro homem autorizado a paquerá-la? Talvez sim, porém, da forma como ocorre diante de uma acompanhante, provavelmente não. O "peso" ou a "importância" de uma relação entre mulheres, tal como Butler (2000) aponta sobre o termo "matter" de seu trabalho Bodies that matter, não é o mesmo que uma relação heterossexual.

Isso reflete notadamente as cristalizações do sexismo no modo de organização social, que se traduz na supremacia e autoridade de um sexo sobre o outro, justificada, na maioria dos casos, pelo essencialismo biológico, pautado na dicotomia homem/mulher e masculino/feminino e na rígida fronteira entre os sexos e os gêneros. Muitos estudos têm demonstrado que, na grande maioria das civilizações, há a prevalência da dominação masculina (e a masculinidade vista como atributo natural dos homens), configurando, assim, o machismo - efeito do pensamento androcêntrico - enquanto determinante das desigualdades nas relações entre os sexos e os gêneros.

Sendo assim, para a compreensão dos inseridos nesse discurso hegemônico, é causa de espanto uma mulher abdicar da relação com um homem (visto como superior e complementar a ela) para estar com outra mulher, especialmente se ela corresponder aos padrões de gênero esperados de seu sexo - ser fisicamente atraente, feminina, e, por isso, desejável. A relação lésbica surge como abjeta ${ }^{10}$ diante da visão heteronormativa e androcêntrica, pois

[...] parece que a homossexualidade feminina não se coloca como algo que estaria em oposição à heterossexualidade, como é o caso da homossexualidade masculina, mas antes como algo que está em oposição à própria sexualidade como um todo, uma vez que essa pertence a um universo falado (do falo?) que seria justamente o universo masculino. (PORTINARI, 1989, p. 45) 
Trata-se aqui de uma referência à Butler (2003, p. 81) em sua crítica à lógica lacaniana de sexuação articulada ainda à primazia fálica (metáfora do pênis). Mesmo que tentando ir 'além das concepções freudianas' em seu texto sob o caso da jovem homossexual, Lacan, segundo Butler, sob um ponto de vista heteronormativo, "presume que a homossexualidade feminina advém de uma heterossexualidade desapontada". Na verdade, Butler não deixa de ter razão nessa crítica já que tal afirmação só é possível quando se considera o desapontamento, primeiro, em relação à ausência de falo na mulher (o que justifica teoricamente dizer que não existe um significante que a represente) e, de outro lado, à frustração em relação ao amor do pai não correspondido ao que Butler rebate dizendo que, por essa lógica da 'frustação/desapontamento' poder-se-ia igualmente compreender "que a heterossexualidade provém de uma homossexualidade desapontada", já que tanto para a menina quanto para o menino, segundo a psicanálise, é a mãe o primeiro objeto de amor.

Todavia, ela explica que essa conclusão tem "um ponto de vista masculino e heterossexualizado, o qual toma a sexualidade lésbica como recusa da sexualidade per se" (ato sexual, gozo fálico e gozo no corpo), em favor do amor, suposto substituto da falta no Outro. Isto implica em desdobramentos que reforçam a tese de que à mulher interessa mais o amor do que o sexo independentemente de sua orientação sexual. Segundo Seddon (2003), esta articulação lacaniana que tenta teorizar a homossexualidade feminina não apenas a partir da primazia do falo, mas sim a partir do amor, reposiciona a mulher homossexual de perversa (enquanto aquilo que supõe ser o objeto faltoso na mãe) para histérica:

Nos anos 60, Lacan faz uma aproximação diferente da homossexual, deslocando-se a polêmica para o amor, como um substituto do falo. Enquanto a mulher heterossexual dá no amor o que não tem por meio da mascarada, com o fim de obter no corpo do amado o significante do seu desejo, isto é o falo, a mulher homossexual se orgulharia de dar o que não tem, para outra mulher, em uma atitude de desafio em relação ao pai. Tratar-se-ia de um amor cortês entre as mulheres homossexuais. O amor homossexual coloca seu interesse principalmente na feminilidade, "em todas as formas, inclusive inconscientes, da homossexualidade feminina" [...] (SEDDON, 2003, p. 8)

Todavia, uma outra concepção insurge na teoria quando Lacan estipula as fórmulas da sexuação. Nesse caso,

A feminilidade encontra-se dividida perante a castração e esta divisão exerce uma determinação da identidade e do gozo feminino. Uma mulher sente-se, em parte presa ao 
gozo fálico, e em parte presa no gozo do Outro. Lacan aproximou a homossexualidade feminina de um discurso de amor e seu interesse pela feminilidade é enriquecido a partir do gozo feminino. O amor homossexual não tomaria o amor como um significante do falo, mas dirigir-se-ia para um gozo do Outro, gozo sem riscos. Por isso, e não pelo fato de possuir uma estrutura perversa, que a homossexual não esperaria nada do discurso analítico [...] (SEDDON, 2003, p.

9)

Vemos que estas articulações teóricas parecem ganhar força na fala de algumas participantes de nossa pesquisa:

Eu dei aula pra uma mulher e eu comecei a sacar que ela estava meio a fim de mim. E rolou de eu ficar com ela. Só que ela tem namorado homem, entendeu? Acho que pelo fato assim de alguma decepção. (Fernanda, 25 anos).

Acho que em alguns casos sim, mas no meu caso não. Já existe uma coisinha lá dentro, já existe... uma sementinha que quando ocorre isso, acorda. [...] sempre pensei dessa forma. Porque é a minha realidade. Eu não me frustrei com homem. Se eu quisesse ter casado com homem eu teria casado, e todos os namorados que eu tive, todos queriam ficar comigo! Então... mas, é que já existia mesmo alguma coisa. Já existia. (informação verbal - Janaína, 47 anos)

Por fim, a crítica de Butler em relação à sexuação (homem, mulher) é que justamente ela prescindiria de uma primazia fálica ou mesmo de um sentimento já que as questões de gênero e do sexo biológico são propriamente performatividades discursivas, de modo que o corpo não antecede a linguagem, logo, se a mulher é 'não-todo', não tem acesso à linguagem, não é porque nela falta-Ihe algo (objeto) que lhe permita ter um signficante que lhe represente no inconsciente, mas sim, porque assim se lhe interpreta no campo sócio-histórico-cultural. Welzer-Lang (2001, p. 461) diz que, fortalecida pelo machismo e pela heteronormatividade, a dominação masculina se tornou hoje uma evidência. Baseado em uma crença natural de que os homens são superiores às mulheres, o autor diz que "os homens dominam coletiva e individualmente as mulheres. Esta dominação se exerce na esfera privada ou pública e atribui aos homens privilégios materiais, culturais e simbólicos".

Rich (1986), sobre isso, problematizou nos anos 80 (período em que o feminismo estudava veementemente as causas da dominação masculina) que se diz que as mulheres escolhem mulheres por causa de homens opressores e indisponíveis emocionalmente, mas que, ao contrário, não se questiona por que há mulheres que seguem tentando ter relacionamentos emocionalmente insatisfatórios e/ou com homens opressores. Leonel (1999) clarifica essa questão 
apontando que, nesse caso, seria mais lógico dizer que a experiência heterossexual não prospera porque o desejo é direcionado para mulheres, e não que a lesbianidade é escolhida em razão de uma má experiência com um homem. Segundo diz, há "lésbicas que, a despeito de terem tido ótimas relações com homens, acabaram preferindo se relacionar sexualmente com mulheres" (LEONEL, 1999, p. 19).

\title{
Heterossexualidade compulsória e opressão feminina
}

Para entender a manutenção e (re)produção das normativas de gênero e sexuais, Rich (1986) usa o conceito de heterossexualidade compulsória, uma instituição que se concentra nos muitos tipos de intensa pressão que a sociedade exerce especialmente sobre as mulheres para garantir que a heterossexualidade se torne destino comum de seu sexo. As sexualidades são produzidas a partir do equivalente geral da heterossexualidade, ou seja, é vista como norma compulsória que, investida de poder, desqualifica, desacredita, vulnerabiliza e oprime toda e qualquer outra forma de expressão das sexualidades. Além disso, a heterossexualidade compulsória contribui com a produção da opressão dos homens sobre as mulheres, a legitimação das relações afetivo-sexuais heterossexuais, e manutenção da dominação masculina:

\begin{abstract}
O sexo torna-se o mais importante, torna-se a pauta do dia desde que encerrado nos limites do inteligível, da norma. Por isso, algumas Feministas apontam a heterossexualidade compulsória justamente como sistema que acomoda e hierarquiza as relações de gênero, onde o homem é o modelo para todas as relações, inclusive aquelas na qual ele não está presente, a explicação está ancorada na sua falta, como o argumento da falta do pênis, da falta de um homem de verdade para pôr fim as relações lésbicas. (LESSA, 2004, s.p.)
\end{abstract}

Rich (1986, p. 46) afirma que nos textos feministas supõe-se que "a heterossexualidade é a 'preferência sexual' da 'maioria das mulheres', implícita ou explicitamente"11. Sendo assim, escreveu sobre a heterossexualidade compulsória para “incentivar as feministas heterossexuais a analisar a heterossexualidade como instituição política que arrebata o poder às mulheres" ( $\mathrm{RICH}, 1986$, p. 41). A autora ainda aponta outras instituições que têm controlado tradicionalmente as mulheres: a maternidade, a família nuclear e a exploração econômica. Exemplifica com a atuação dos profissionais da saúde em relação às questões "femininas":

[...] os conselhos que os homens profissionais da saúde dão às mulheres, especialmente nos âmbitos da sexualidade no casamento, na maternidade e nos cuidados infantis, têm 
feito eco dos ditados da economia de mercado e do papel que o capitalismo tem necessitado que as mulheres executem na produção e/ou na reprodução. [...] Nenhum dos conselhos dos 'experts' tem sido nem especialmente científico, nem desenhado para as mulheres; têm refletido necessidades masculinas, fantasias masculinas sobre as mulheres e o interesse masculino em controlá-las [...]. ( $\mathrm{RICH}, 1986$, p. 46-47)

Mesmo com as lutas e conquistas feministas e com a emancipação das mulheres, a heterossexualidade compulsória ainda se faz presente na atualidade, oprimindo-as de formas claras ou sutis. Como Castañeda (2006) aponta, o machismo existe, mas se tornou invisível. Podem-se observar, na fala das entrevistadas, atitudes que falam mais claramente da opressão masculina sobre as mulheres no campo das sexualidades, exemplificando situações, ou ainda baseando-se em uma "origem" das lesbianidades e apresentando o ideário do sistema heteronormativo tendo a mulher como objeto a serviço do prazer do homem. Por exemplo:

Sei lá, acho que, por decepção, elas falam que homem é mais insensível; mulher é mais sensível, mais compreensiva. Homem é mais bruto. [E o que você acha disso?] [pausa] Eu concordo. Sei lá, porque eu trabalho no meio de dez homens e três mulheres, sabe? E eles só pensam em... vê uma mulher e fala: ‘Essa daí dá pra mim pegar, transar. Essa aí é boa, não sei o quê'. Sabe? esse tipo de coisa assim. Só fala em transar. [E você acha que tem mulheres que ficam com mulheres por causa de homens assim?] Eu acho que sim. Homem é sem vergonha. Tem mulheres, né? Tem mulheres sim. Mas homem é mais, pelo instinto. Pelo meu convívio lá, sabe? Até tive uma discussão com um amigo de trabalho meu por causa disso. Um dia, chegou uma mulher, uma aluna lá, e ele falou: 'Ah, essa mulher é boa, não sei o quê, transar, não sei o que lá'. Eu falei: 'Ô, você só pensa em transar, meu? Você não pensa em fazer um carinho, sabe? Bater um papo, trocar uma idéia?'. Ele falou assim: 'Não...'. Eu falei: 'Mas você só fala em transar, meu'. Então eu acho que... vai daí também. (informação verbal - Fernanda, 25 anos)

Marcela relatou que, muitas vezes, devido à insensibilidade e à falta de interesse de muitos homens no prazer das parceiras, e por privilegiarem seu próprio prazer, esses acabam não as satisfazendo sexualmente, o que as fazem procurar alguém que cumpra esse papel. Para ela, uma mulher saberia proporcionar melhor prazer à outra, especialmente por conhecer intimamente seu corpo e seu prazer e porque tende a ser mais carinhosa e sensível:

Ó, eu penso assim. A mulher, ela sabe todo lugar onde a mulher gosta de ser tocada, porque ela também é uma 
mulher. E o homem, não que eu tou falando mal de homem, porque eu sei que tem muitos homens carinhosíssimos, que escuta as mulher falando e tal. Mas, a maioria, de $100 \%$, $90 \%$ são bruto, pensam mais nele do que nas parceira, entendeu? Eu tive relacionamentos com mulheres casada que elas queriam largar do marido pra ficar comigo, mas eu nunca permiti isso porque tinham filhos, e esse negócio de estragar lar não é comigo não. Então, eu penso assim, sabe, eu vejo isso. A mulher sabe onde a outra gosta de ser tocada, o carinho, agora o homem não [faz]. Já que eu nunca tive relação com homem eu não posso nem tá falando, mas pelas coisas que eu ouço falar. Meu irmão mesmo, as coisas que ele fala pra mim que ele faz com as mulheres, pelo amor de Deus. (informação verbal - Marcela, 42 anos)

Castañeda (2006), em uma análise do machismo, ressalta que a construção da masculinidade baseia-se, entre outros fatores, na demonstração repetida de virilidade e da disposição sexual, e na busca de múltiplas conquistas sexuais. Para ser visto como um "verdadeiro homem", é necessário estar, a todo o momento, preparado para o ato sexual, pronto para uma mulher, e aquele que recusa uma oportunidade tem uma masculinidade duvidosa. Essa insegurança masculina de ser visto como "mulherzinha" ou "veado" faz com que alguns recorram sexualmente às mulheres como forma de validação de sua masculinidade, o que nem sempre (ou quase nunca) é agradável para elas:

Muitos homens, para demonstrar sua masculinidade, acham importante exibir desejo continuamente e aludir constantemente à sua vida sexual [...] Tal atitude conquistadora [...] Não apenas é inapropriada, como também distorce todas as interações entre homens e mulheres, porque contamina todos os contatos entre eles. Eles tendem a ver as mulheres, sejam elas amigas, colegas ou perfeitas desconhecidas, de uma maneira erotizada que é desagradável para muitas delas. (CASTAÑEDA, 2006, p. 209)

Para Rich (1986, p. 55-56), a dominação dos homens surge como um "grupo de forças onipresentes que vão desde a brutalidade física até o controle da consciência", e impõe a heterossexualidade às mulheres por meios diversos: negando às mulheres explorarem suas diversas formas de vivência das sexualidades; impondo a elas a sexualidade masculina heterossexual; dirigindo ou explorando seu trabalho para controlar o produto; confinando-as fisicamente e proibindo-lhes o movimento; usando-as como objeto de troca entre homens; colocando obstáculos à sua criatividade; negando-Ihes amplas áreas de conhecimento social e cultural. Assim, os espaços tradicionais de agitação do feminismo são poderosas instituições de expressão da supremacia masculina: a família, a religião, a discriminação no trabalho e a dependência econômica; a reprodução forçada, a 
educação tendenciosa, a falta de direitos, o status civil etc. (RUBIN; BUTLER, 2003, p. 176).

Esse domínio sobre elas se tornou quase invisível ao ser considerado natural e inevitável. A partir deste ponto de vista, "as mulheres são consumíveis tanto quanto possam ser satisfeitas as necessidades sexuais e emocionais do macho" ( $\mathrm{RICH}, 1986$, p. 60).

\title{
Bissexualidades femininas e androcentrismo
}

Clarificamos aqui que orientação sexual corresponde ao desejo/atração sexual. Deste modo, uma pessoa de orientação sexual bissexual, por exemplo, mesmo desejando homens e mulheres afetiva e sexualmente, pode assumir uma identidade tanto na lesbianidade (sentir-se lésbica) quanto na bissexualidade (sentir-se bissexual) ou heterossexualidade (sentir-se heterossexual). Apenas sentir desejo/atração pelo mesmo sexo ou ter relações/práticas sexuais com pessoas do mesmo sexo não define a subjetividade. É necessário sentir-se subjetivamente nesse "lugar".

Assim, não podemos ser reducionistas em acreditar que a simples frustração com um homem torne uma mulher lésbica, pois isso seria equivalente a dizer que se o machismo e a opressão da heterossexualidade compulsória deixassem de existir, não haveria lesbianidade. A orientação sexual do desejo homossexual, assim como a heterossexual e a bissexual, é legítima.

Gimeno Reinoso (2005, p. 43-44) fala sobre os significados dos vínculos entre mulheres dentro do sistema heteronormativo e androcêntrico, e como as ligações entre elas ocorrem de forma diferenciada das relações que os homens criam entre si - visando o controle da sexualidade feminina:

\begin{abstract}
Os vínculos emocionais e de solidariedade entre mulheres são, para Rich, vínculos com os quais elas se ajudam umas às outras para resistir à opressão, são vínculos de resistência, enquanto que, ao contrário, os vínculos de solidariedade entre homens são a base mesma do patriarcado ${ }^{12}$, os vínculos que criam entre eles têm com o objetivo de oprimir as mulheres.
\end{abstract}

O que se pode problematizar a partir dessa discussão é que, e é o que sugere a leitura de Rich (1986) e Wittig (1978), no caso das mulheres de orientação sexual bissexual, diante do machismo e da construção social da (hiper)sexualidade masculina e a conseqüente opressão das mulheres, a lesbianidade pode ser vivida (e escolhida), consciente ou inconscientemente, como uma resistência à dominação masculina. No caso de poder haver uma escolha, o machismo pode contribuir para que essa eleição seja pela relação com uma mulher, menos presa a esse sistema (não que não possam agir da mesma forma opressiva). 
Marcela e Marina acreditam em uma propensão à bissexualidade, ou uma curiosidade de mulheres que nunca tiveram uma experiência homoerótica e têm algum tipo de desejo por mulheres, acreditando que o desejo homossexual é presente em todas as pessoas:

Tem muitas que eu escuto falando que têm curiosidade. Muitas fazem essa pergunta pra mim, sabia? Pessoas que não são, me vê e pergunta como que é, como que faz e eu explico, mostro tudo como que tem que fazer, como que faz [risos] [...] Ela deixa desenvolver mais, ela tem curiosidade, quer conhecer, acaba conhecendo, gostando e continuando e aí não tem como. [Mas depois elas poderiam voltar a ficar com homens novamente.] Isso. Só que a maioria não volta, viu? Por experiência própria. [...] toda mulher no seu íntimo ela deseja uma mulher, eu penso isso. Que eu já tive várias e todas falam a mesma coisa. Eu acho que no íntimo da mulher, todas as mulheres desejam no fundo. Ou não sei se é pra, sei lá, pra saber, pra saber como é que é, alguma coisa, mas, no fundo há um desejo por mulheres. Uma mulher deseja outra. (informação verbal - Marcela, 42 anos)

$\mathrm{Na}$ verdade, eu acho que todo mundo é propenso a ficar com homem e com mulher, né? Claro que a forma de se reproduzir é um homem e uma mulher, mas a sociedade leva a gente a não ficar com uma mulher. Porque tem que ter o cara que trabalhar, e a mulher tem que lavar a roupa, o homem não pode limpar a casa, e a mulher é que tem que ir pegar no pesado dentro de casa. Então é uma... é a sociedade mesmo: o homem tem que ficar com uma mulher e a mulher tem que ficar com um homem! (informação verbal - Marina, 23 anos)

Kinsey já dizia nos anos 1940, que é uma minoria da população que tem comportamento sexual exclusivamente hetero ou homossexual. Ocorre que a maioria cumpre com os pressupostos da heterossexualidade. $O$ interesse de sua pesquisa era demonstrar que o desejo sexual humano é variável ao longo da vida e pode ser fluido (GIMENO REINOSO, 2005). Contudo, "seu trabalho tem sofrido um processo irreversível de má interpretação, em que é citado exatamente para demonstrar o contrário do que ele queria demonstrar" (GIMENO REINOSO, 2005, p. 215). Ou seja, naturalizase a hetero e a homossexualidade como únicas formas de desejo humano, naturais, opostas e fixas - tal como se naturalizam os sexos e os gêneros.

Gimeno Reinoso (2005) fala sobre estudos acerca de uma ampla quantidade de mulheres que experimentam desejos por outras no decorrer da vida, ou como seu desejo é cambiante. Ela lembra uma pesquisa do espanhol Ramón Serrano Vigenz, de 1961, com 1.471 mulheres, na qual seis entre dez delas disseram ter tido desejos de 
ter relações sexuais com alguma amiga ou conhecida, sendo que três entre as dez levaram seus desejos à prática.

Entretanto, a heterossexualidade compulsória e a crença na superioridade dos homens também têm impacto na construção dos modos de subjetivação das mulheres que sentem atração afetivosexual por outras no sentido de fazer muitas delas rejeitar parceiras bissexuais. A bissexualidade, vista no discurso hegemônico dualista como uma indecisão entre a hetero e a homossexualidade, traz a insegurança de que a primeira seja escolhida frente à visão da supremacia masculina. Pérez (2003) e Brown (1995) comentam esse posicionamento: "Em geral se valoriza de forma negativa iniciar um jogo de sedução com uma bissexual ou com uma heterossexual, por considerar que se corre o risco de apaixonar-se sem ser correspondida" (PÉREZ, 2003, p. 7) ${ }^{13}$;

\begin{abstract}
Para lésbicas, a não-fixidez de uma identidade lésbica diz mais fortemente sobre assuntos de confiança e previsibilidade. Se uma mulher sempre e apenas tiver se relacionado sexual e afetivamente com outras mulheres, ela pode ser percebida como mais 'segura' de se investir para relacionamentos do que uma mulher que teve experiências heterossexuais passadas. Golden sugere como esta questão de definição é determinante; em algumas comunidades lésbicas, é mais importante o fato de uma mulher alguma vez ter se relacionado sexualmente com um homem do que já ter se relacionado sexualmente com mulheres. Nessa análise, uma mulher formalmente virgem não tem nenhuma lealdade aparente às relações heterossexuais, enquanto aquelas que tiveram experiências heterossexuais podem ser percebidas com o risco por voltar para os homens. (BROWN, 1995$, p. 7$)^{14}$
\end{abstract}

Nesse sentido, se uma mulher que se diz lésbica tem qualquer experiência sexual com um homem, ela não tem a reputação de uma "lésbica pura". Entretanto, a identidade lésbica não está diretamente relacionada apenas com a orientação do desejo sexual, mas com o fato de tornar-se sujeito de seu desejo e de sua sexualidade em um mundo onde as mulheres são vistas, ao contrário, como objetos.

Acreditar que as mulheres de orientação sexual bissexual terminariam uma relação lésbica para estar com um homem apenas porque ele é homem, além de ilegitimar o desejo bissexual, é se prender ao androcentrismo e aos ideais do sistema heterossexual. Por outro lado, também se pode suspeitar que desejar que a parceira não retorne aos homens se deva à crença na reinserção ao universo de opressão e dominação masculina, ao qual a "ex" pode ser igualmente submetida. Por ser vista como aquela que foi deixada, a ex-parceira pode ficar a mercê de um posicionamento sexista inferiorizante acreditando, por exemplom que um homem poderia 
resgatar a fêmea para o mundo "normal". Nesse sentido, um homem seria capaz de satisfazer afetiva e sexualmente uma mulher.

\section{(Lesbo) Unindo mulheres}

Outro mecanismo de força da heterossexualidade compulsória é "converter em invisível a possibilidade lésbica" ( $\mathrm{RICH}, 1986, p .65)$, não a considerando como uma experiência autêntica entre mulheres, mas "um mero refúgio frente aos abusos masculinos. [A experiência lésbica tem sido] "o fato mais violentamente eliminado da experiência feminina" (RICH, 1986, p. 78-81).

A partir disso, Rich (1986, p. 65) ressalta que a "heterossexualidade pode não ser uma 'preferência' em absoluto, e sim algo que tem sido imposto, gestionado, organizado, propagado e mantido [tanto] a força" como de forma subliminar. Mulheres (e homens) são levadas a serem heterossexuais, reforçadas pela ideologia do amor romântico heterossexual que "sobressai desde a infância nos contos de fadas, na televisão, no cinema, na publicidade, nos cortejos nupciais" ( $\mathrm{RICH}$, 1986 , p. 61). Especificamente, Eduarda comenta como essa instituição foi colocada sobre ela:

Então, antes de descobrir, eu tinha primas tudo e as minhas primas eram loucas por causa de homens, tinha coisas de homem, pasta com fotos de homem, tinham um monte de coisas, daí eu fui conversando com elas, montei a minha pasta com fotos de homens, tive essa fase assim e era legal, tudo. Mas eu achava bonito, eu olhava os homens ali e... bonito! Eu achava bonito, mas não tinha nada além, não tinha nada de mais, era só bonito. (informação verbal Eduarda, 18 anos)

Então, [risos] eu fiquei com esses meninos, três deles, foi mais por pressões externas que pela minha vontade, porque, por mim, eu tava tão bem, tão feliz sozinha. Mas, um deles foi muito insistente, muito insistente, muito insistente, daí, 'Tá bom, vai, pra você me deixar em paz'. O outro, uma amiga minha que ficou me cutucando, cutucando, daí... foi também. Mas até que foi bonzinho, até que foi. Não teve muita graça, mas também não arrancou pedaço, sabe? Mas era uma coisa que eu poderia viver sem, esses relacionamentos que eu tive com homem. O outro também foi de ficarem me empurrando; empurrando ele de um lado e me empurrando do outro. Ai, horrível. E um, que foi o único que eu acho que, também, é claro, me empurraram, mas esse foi mais interessante, mais legal, porque a gente conversou mais. Acho que por isso que eu gostei [risos]. (informação verbal - Eduarda, 18 anos)

Gimeno Reinoso (2005, p. 253) ressalta que "as mulheres querem também viver relações igualitárias que não lhes roubem suas energias emocionais em nome de um amor que sempre exige mais do 
que oferece a elas". Todavia, Rich (1986, p. 79-80) aponta falsas dicotomias que impedem de ver a instituição da heterossexualidade compulsória em sua totalidade e como a não análise desta retira a opção de escolha às mulheres de não estarem abandonadas à sorte:

\begin{abstract}
[...] casamentos 'bons' frente aos 'maus'; 'casamento por amor' frente ao casamento pactuado; sexo 'liberado' frente à prostituição; coito frente à violação; [...] Dentro da instituição existem, claro, experiências diferentes qualitativamente, mas a falta de escolha segue sendo a grande realidade que não se reconhece e, na ausência de escolha, as mulheres seguirão dependendo do azar ou da sorte das relações concretas e não terão poder coletivo para determinar o significado e o lugar da sexualidade em suas vidas.
\end{abstract}

Se "a libertação das mulheres começou no plano econômico, ainda está por realizar, no plano psicológico, um trabalho de conscientização que lhes permita a autonomia e as liberte da sua dependência afectiva" (LAGO; PARAMELLE, 1978, p. 49). Essa afirmação de forma alguma quer dizer que as mulheres, para conquistar liberdade, têm como única saída tornarem-se lésbicas apesar de, segundo Gimeno Reinoso (2005), essa ser uma das possibilidades -, porém, diz de uma não-superiorização ideológica dos homens e a consciência da expressão homossexual das sexualidades.

A heterossexualidade compulsória - construída na desigualdade entre os sexos e os gêneros - conduz as mulheres a execrarem umas às outras, em uma competição contínua entre elas. Primeiramente, essa concorrência se dá pela conquista do homem (visto como superior), pois é o que lhe dá referência de existência diante do mundo: quando se fala de um casal heterossexual, dificilmente se fala "o homem da ...", mas "a mulher do ...". A categoria mulher, perante o homem, é propriedade, é objetificada.

Em segundo lugar, a competição se dá pela conquista do "arsenal para agradar os homens": o ideal de beleza das mulheres, ou seja, a feminilidade em facetas diversas - que se configura na modelação do corpo ideal (magreza, cintura fina, cabelo liso, seios grandes, nádegas empinadas, entre outros); nos comportamentos ideais (delicadeza, sensibilidade, fragilidade, continência, entre outros). Tudo isso está sujeito, ainda, a qual categoria é atribuída à mulher (PARKER, 1991): as respeitáveis (esposas, namoradas, moças de família) devem estar dentro dos níveis de decência moral enquanto das não respeitáveis (mulheres da rua, prostitutas e lésbicas) se espera atitudes opostas de liberação sexual e imoralidade.

Essa competição em prol dos homens faz com que as mulheres olhem para suas iguais como rivais e ínvidas daquelas que alçaram a estados correspondentes ao que as normativas de gênero e sexuais 
atestam como ideais: ter um namorado, se casar, ter filhos, ter um corpo dentro dos padrões de feminilidade desejável. Olhar entre si sem o referencial homem possibilitaria às mulheres um olhar mais solidário e com menos embates/inveja. Essa competição/rivalidade entre mulheres, que a heterossexualidade compulsória em combinação com o androcentrismo promove, mantém a dominação masculina, pois não permite a elas articularem-se/aglutinarem-se de forma a combater essa dominação, bem como não permite que olhem umas às outras de forma erotizada - sendo isso percebido com enorme repulsa e aversão. Essa ligação entre mulheres não seria necessariamente afetivo-sexual - como o pode ser também -, mas uma ligação livre das amarras hegemônicas da heteronormatividade e da superioridade masculina.

De acordo com Lago e Paramelle (1978, p. 49), esta "tomada de consciência permitirá à mulher escolher os seus parceiros sexuais e afectivos [sejam homens ou mulheres]. Ela poderá igualmente decidir sublimar as suas tendências homossexuais, transformando-as numa aliança com as outras mulheres", e não em uma inveja uma das outras e/ou competição pelos homens.

Hite (1985, p. 307), em seu profundo estudo sobre as sexualidades femininas, já pontuava a questão da lesbianidade política:

\begin{abstract}
É importante que as mulheres reconheçam sua potencialidade sexual por outras mulheres. Se queremos nos fortalecer, temos que aprender a amar, respeitar, honrar, ser ambiciosas e interessadas em outras mulheres. Isso inclui descobrir nas outras a atração física e a possibilidade de intimidade sexual. Enquanto só pudermos nos relacionar sexualmente com homens porque são 'homens' (e enquanto os homens só puderem se relacionar com mulheres porque são 'mulheres'), estaremos dividindo o mundo exatamente nas duas classes que estamos tentando transcender.
\end{abstract}

As chamadas "explicações" para as lesbianidades (frustração física e emocional ou "trauma" com um homem, ou rejeição por eles pela falta de atratividade) são fundamentalmente machistas - têm sempre como referência os homens, a masculinidade e genitalização do desejo sexual centrada no pênis e na penetração. A partir da análise das entrevistas, o que se notou foi que, ao menos em relação à "frustração com os homens", o que caberia melhor aqui "frustração com o machismo", esta possa, talvez, contribuir para o despertar da consciência do desejo homossexual, porém, nunca determinante da lesbianidade. Tal como Gayle Rubin aponta, em entrevista com Judith Butler (RUBIN; BUTLER, 2003, p. 173), o que há de interessante e especial no que é chamado de lesbianidade é o seu conteúdo sexual da atração e do desejo de uma mulher por outra, e nada tem a ver com a figura masculina. 
O que vemos com esses relatos é que as normatividades de gênero e de sexualidade estão presentes em nossa sociedade atuando na produção dos modos de subjetivação, desvalorizando e dessexualizando as mulheres e relegando as lesbianidades a um lugar de abjeção. Reconhecer a existência lesbiana é rever todo o sistema heteronormativo e androcêntrico, é desconstruir o sistema de sexo binário e ir além do sexo, pois podemos pensar os modos de vivenciar o prazer, a sexualidade e as relações afetivo-sexuais não como baseadas na natureza ou na biologia, na masculinidade genitalizada, ou mesmo como determinismos culturais, mas produzidas, construídas, e, exatamente por isso, múltiplas e passíveis de mudança. Reconhecer a potencialidade sexual entre mulheres é, a partir da abjeção de uma subjetivação/vivência/singularidade das sexualidades, rever o sistema hegemônico.

Estudos mais aprofundados para responder a essa temática se fazem necessários. O que não se pode perder de vista é que inserir os discursos sobre as lesbianidades no sistema androcêntrico e heteronormativo é negar a legitimidade desse desejo, fazendo visíveis modos estigmatizados e estereotipados para encobrir suas variedades de existência múltiplas, fluídas e mesmo contraditórias, ajustando-as aos padrões inteligíveis homogeneizantes.

Para nós, psicólogos, se faz necessária uma análise crítica dos sentidos e significados que as lesbianidades recebem, pois o que temos são normas, não essências de subjetivação já que as identidades sexuais e de gênero (homem, mulher, gay, lésbica, transexual, etc.) não são constructos psicológicos, mas atribuições sócio-históricas e culturais, assim como são construídos os gêneros e os sexos para a manutenção de uma certa ordem sexual e social. 0 que sabemos é que essa mesma norma produz desigualdades e hierarquias e, arbitrariamente, considera algumas formas de vivenciar as sexualidades como inteligíveis, legítimas e normais e outras como ininteligíveis, ilegítimas e anormais. Por isso, é a própria construção das normas que deve ser posta em questão, e não a forma como as pessoas vivem suas sexualidades, pois é claro que esta é diversa assim como a própria existência humana.

\section{Referências Bibliográficas}

BUTLER, J. Corpos que pesam: sobre os limites discursivos do "sexo". In: LOURO, G. L. (Org.). O corpo educado: pedagogias da sexualidade. Tradução Tomaz Tadeu da Silva. Belo Horizonte: Autêntica, 2000. p. 151-172.

Problemas de gênero: feminismo e subversão da identidade. Tradução Renato Aguiar. Rio de Janeiro: Civilização Brasileira, 2003. BROWN, L. S. Lesbian identities: concepts and issues. In: D'AUGELLI, A. R.; PATTERSON, C. J. (Eds.). Lesbian, gay and bisexual 
identities over the lifespan: psychological perspectives, New York: Oxford University Press, 1995. p. 3-23.

CAPRIO, F. S. Homossexualidade feminina. Tradução Frederico Branco. São Paulo: Instituição Brasileira de Difusão Central, 1960.

CASTAÑEDA, M. O machismo invisível. Tradução Lara Christina de Malimpensa. São Paulo: A Girafa Editora, 2006.

A experiência homossexual: explicações e conselhos para os homossexuais, suas famílias e seus terapeutas. Tradução Brigitte Hervot e Fernando Silva Teixeira Filho. São Paulo: A Girafa Editora, 2007.

FOUCAULT, M. História da sexualidade I: a vontade de saber. Rio de Janeiro: Graal, 1988.

FRASER, N. Políticas feministas na era do reconhecimento: uma abordagem bidimensional da justiça de gênero. Tradução Heloísa Eugênia Villela Xavier. In: BRUSCHINI, C.; UNBEHAUM, S. G. (Org.). Gênero, democracia e sociedade brasileira. São Paulo: Fundação Carlos Chagas/34, 2002. p. 59-78.

GIMENO REINOSO, B. Historia y análisis político del lesbianismo: la liberación de una generación. (Colección Libertad y Cambio) Editorial Gedisa: Barcelona, España, 2005.

HITE, S. Lesbianismo. In: _.. O relatório Hite. Tradução Ana Cristina César. 15a ed. São Paùlo: Difusão Editorial, [1976] 1983. p. 285-308.

LAGO, M.; PARAMELLE, F. A mulher homossexual: ensaio sobre a homossexualidade feminina. Tradução Maria Augusta Ramalho S. Campinas, SP: Publicações Europa-América, 1978.

LEONEL, V. Lésbicas. Rio de Janeiro: Velocípede (Coleção e.n.t.e.n.d.e.r.), 1999.

LESSA, P. Que 'babado' é esse? Corpo, sexualidade e lesbiandade no gay pride. Labrys, estudos feministas, n. 6, ago./dez., 2004. Disponível em: <http://www.unb.br/ih/his/gefem/labrys6/lesb/patricia.htm>. Acesso em: 18 out. 2007.

MOTT, L. O lesbianismo no Brasil. Porto Alegre: Mercado aberto, 1987.

PARKER, R. G. Corpos, prazeres e paixões - a cultura sexual no Brasil contemporâneo. Tradução de CAVALLARI, M. T. M. São Paulo: Editora Nova Cultural, 1991.

PÉREZ, G. C. Relaciones entre mujeres. Relaciones entre mujeres. In: Primera Reunión Regional Sexualidades, salud y derechos humanos en América Latina; Universidad Peruana Cayetano Heredia, Lima, Perú, 2003. Anais eletronicos... Universidad Peruana Cayetano Heredia, Lima, Perú, 2003. Disponível em: <http://www.ciudadaniasexual.org/publicaciones/5.pdf>. Acesso em: 25 jan. 2007. 
PORTINARI, D. O discurso da homossexualidade feminina. São Paulo: Brasiliense, 1989.

$\mathrm{RICH}, \mathrm{A}$. Heterosexualidad obligatoria y existencia lesbiana, 1980. In: Sangre, pan y poesía: prosa escogida: 1979-1985. Icaria: Barcelona, 1986. p. 41-86.

RUBIN, G. S.; BUTLER, J. Tráfico sexual - entrevista. Cadernos Pagu, Campinas, n. 21, p. 157-209, 2003.

SEDDON, G. G. A namorada tem namorada. Clínica psicanalítica do sujetio contemporâneo. Estados Gerais da Psicanálise. Segundo Encontro Mundial. Rio de Janeiro, p. 1-18, 2003.

VENCATO, A. P. Algumas garotas preferem garotas: The L Word, sexualidade e as políticas de visibilidade lésbica. In: Reunião De Antropologia Do Mercosul, v. 6, 2005, Montevidéu.

WELZER-LANG, D. The construction of the masculine: women's domination and homophobia. Revista de Estudos Feministas, Florianópolis, v. 9, n. 2, p. 460-482, 2001.

WITTIG, M. El pensamiento heterosexual [1978]. In: EI pensamiento heterosexual y otros ensayos. Tradução de Javier Sáez y Paco Vidarte. p. 45-57. EGALES: Madrid, 2005.

\section{Endereço para correspondência \\ Livia Gonsalves Toledo \\ Programa de Pós-Graduação em Psicologia Universidade Estadual Paulista - Faculdade de Ciências e Letras de Assis, Av. Dom Antônio, 2100 Pq. Universitário CEP 19806-900, Assis-SP, Brasil \\ Endereço eletrônico: liviagtoledo@gmail.com \\ Fernando Silva Teixeira Filho \\ Departamento de Psicologia Clínica Universidade Estadual Paulista - Faculdade de Ciências e Letras de Assis, Av. Dom Antônio, 2100 Pq. Universitário CEP 19806- 900, Assis-SP, Brasil}

Endereço eletrônico: fteixeira@assis.unesp.br

Recebido em: 02/06/2009

Aceito para publicação em: 12/03/2010

Acompanhamento do processo editorial: Anna Paula Uziel

\section{Notas}

${ }^{1} O$ termo lesbianidades é utilizado aqui para nomear processos de subjetivação relativos à orientação sexual e identidades política, sexual e de gênero de mulheres com relações/práticas homoeróticas que se auto-atribuem o nome lésbica ou similar (entendida, sapa, sapata, bolacha, sapatona, sapatão, dyke, lady, fancha, etc.) e sentem-se subjetivamente nesse "lugar" de diferença, de não-heterossexualidade, seja no desejo por, na prática com, ou no sentimento homoerótico por outra mulher, em todos esses âmbitos ou apenas um ou dois deles. É empregado no plural para referenciar todas as possibilidades de vivências das relações afetivosexuais de uma mulher com outra, já que não existe um modelo de ser lésbica ou de relação lésbica. Portanto, entende-se aqui como lésbica uma pessoa que se sente subjetivamente mulher e nesse "lugar" de desejos/sentimentos/práticas homoeróticas. Ainda é importante lembrar que o termo lesbianidade é uma 
proposição do movimento lésbico brasileiro como crítica ao termo lesbianismo, que, devido ao uso do sufixo ismo, tem caráter patologizante.

${ }^{2}$ Além desses discursos serem observados no senso-comum, como vamos verificar nos relatos das entrevistadas, a ciência médica não há muito também apontava argumentações semelhantes. Caprio (1960) fez uma classificação das mulheres homossexuais, as quais ele classificava "invertidas", chamando sua prática de "safismo": 1) Safismo através da luxúria; 2) Safismo profissional; 3) Safismo por necessidade; 4) Safismo por temor. O autor sugeriu que a primeira classificação fosse referente à promiscuidade; a segunda, ao trabalho como exibicionismo sexual pago, oferecendo um espetáculo aos clientes em estabelecimentos próprios (prostíbulos); a terceira, aos casos em que a mulher "não tem acesso a homens", como em penitenciárias, internatos e pensionatos; e a última, a situações traumáticas com homens.

${ }^{3}$ Durante a pesquisa de mestrado foram analisados cinco diferentes estigmas, dentre eles: "o que lésbicas fazem na cama não é "sexo de verdade"", "lésbicas são masculinizadas", "na relação lésbica há uma ativa e uma passiva", "lésbicas ou são promíscuas ou formam casais românticos assexuados" e "lésbicas são mulheres que se frustraram com homens", sendo este último o escolhido para a escrita deste artigo.

${ }^{4}$ Nomes fictícios.

${ }^{5} \mathrm{~A}$ cidade tem pouco menos de 100 mil habitantes, situada no Oeste Paulista, de economia rural.

${ }^{6}$ Todas as citações de Gimeno Reinoso (2005) são versões nossas traduzidas do espanhol.

${ }^{7}$ As masculinas podem ser caracterizadas como as "caminhoneiras" que, segundo Viñulaes (2002, p. 111), é um termo usualmente pejorativo que serve para designar as mulheres cuja estética, atitudes e conduta reproduzem àquelas pensadas como próprias do gênero oposto.

${ }^{8}$ Opinião de um dos visitantes, evangélico, de uma exposição de fotos de mulheres participantes das Paradas de São Paulo e de Curitiba, organizada por Patrícia Lessa, no ano de 2002, e realizada em julho de 2003, na Universidade de Brasília, deixado em um caderno de comentários por ela disponibilizado.

${ }^{9}$ Região da cidade de São Paulo conhecida como com grande frequência de homossexuais.

${ }^{10} \mathrm{O}$ abjeto designa aqui precisamente aquelas zonas 'inóspitas' e 'inabitáveis' da vida social que são, não obstante, densamente povoadas por aqueles que não gozam do status de sujeito, mas cujo habitar sob o signo do 'inabitável' é necessário para que o domínio do sujeito seja circunscrito. (BUTLER, 2000, p. 155)

${ }^{11}$ Todas as citações de Rich (1986) são versões nossas traduzidas do inglês.

${ }^{12} \mathrm{O}$ conceito do patriarcado, ao definir o poder dos pais sobre as mulheres e crianças, apesar "de pretender ser um conceito descritivo da dominação masculina, ele sofre, por não dar o devido valor às mudanças nas relações sociais de sexo e, em particular, às modificações se referem às relações de poder" (WELZER-LANG, 2001, p. 475). Assim, o termo viriarcado, proposto por Nicole-Claude Mathieu (apud WELZER-LANG, 2001), vem sendo usado como um substituto, pois "define como o poder dos homens, sejam eles pais ou não, que as sociedades sejam patrilineares, patrilocais ou não" (WELZER-LANG, 2001, p. 476). Esse poder dos homens sobre as mulheres tem base na visão androcêntrica de mundo e constitui a grande maioria das sociedades.

${ }^{13}$ Todas as citações de Pérez (2003) são versões nossas traduzidas do espanhol.

${ }^{14}$ Todas as citações de Brown (1995) são versões nossas traduzidas do inglês. 